\title{
A Study on Recognition and Assessment of Agricultural Weather-related Disaster Risk
}

\author{
Sijian Zhao, Qiao Zhang, Qian Nie
}

Agricultural Information Institute of Chinese Academy of Agricultural Sciences; Key Laboratory of Digital Agricultural Early-warning Technology, MOA, Beijing China, 100081

\section{农业气象灾害风险识别与评估技术研究}

\author{
赵思健, 张峭, 聂谦 \\ 中国农业科学院农业信息研究所, 农业部智能化农业预警技术重点开放实验室, 北京, 100081
}

\begin{abstract}
In this article, crop's weather-related disaster risk would be recognized and assessed on the basis of time-serial yield data and time-serial weather data, using maize in Xiao County and rice in Lai'an County, that are located in Anhui Province, as a case study. In general, a weather-related disaster is an extreme weather event. More specifically, it is an anomalous weather event. As a consequence, crop yields are expected to appear anomalous too when anomalous weather events appear. According to such a rule, the best relationship between anomalies of crop yield and meteorological variables was figured out through optimal matching. The weather disasters were further ranked according to their contributions to the yield loss risk, and the yield loss risk-related caused by any a weather-related disaster can be assessed by simulation. Such above technologies would play an important role in crop's weather disaster-related risk management, and even support the design of crop's weather-based index insurance.
\end{abstract}

Keywords: Crop; Weather-related disaster risk; Anomaly recognition; Optimal matching; Risk ranking; Risk simulation; Yield trend removing; Deviation analysis

\section{摘要}

本文以安徽省淮北萧县玉米和长江流域来安县水稻 为案例, 在历史产量数据与气象数据的支持下, 根据 气象异常诱发气象灾害、气象灾害导致产量损失的基
本原理, 通过气象异常阈值识别及异常与产量损失关 系的优化匹配, 建立作物产量损失与气象要素异常之 间的最佳匹配关系, 测算各种气象灾害对作物产量损 失的风险度并排序, 实现作物气象灾害的风险模拟评 估, 进而为开展农业气象灾害风险管理, 特别是为开 展农业气象指数保险提供重要的技术支撑。

关键词: 农业; 气象灾害风险; 异常识别; 优化匹配; 风险度排序; 风险模拟; 去趋势; 距平分析

\section{1. 引言}

我国农业生产总体虽呈增长趋势, 但农作物产量年际 间的波动日益加剧, 是普遍存在、不容忽视的问题 ${ }^{[1]}$ 。 农作物产量波动的影响因素大致归结为社会因素、气 象因素及其他一些偶然因素, 其中气象因素、尤其是 气象灾害对作物产量波动的影响最大 ${ }^{[2,3]}$ 。据统计, 自 20 世纪 90 年代以来, 我国几乎每年都会暴发重大 的气象灾害, 包括干旱、洪涝、冷害、台风、寡照等。 农作物平均每年受灾面积约为 $46,966 \mathrm{khm}^{2}$, 占总播种 面积的 $30.57 \%$, 平均年成灾面积约为 $24,774 \mathrm{khm}^{2}$, 占播种面积的 $16.13 \%$, 给农作物产量造成很大的影 响。为此, 亟需对农业生产的气象灾害风险进行有效 评估, 并采取有效的风险管理措施（例如农业保险） 保障农业生产的持续稳定。

与农业气象灾害风险相关的研究很多, 有代表性 的包括: 杜鹏等较早就提出农业气象灾害风险的体系 和特点 ${ }^{[4]}$, 李世奎等提出农业气象灾害风险评估体系 及模型 ${ }^{[5]}$, 李志明等 ${ }^{[6]}$ 、王丽媛 ${ }^{77}$ 等对农业气象灾害 风险评估进行综述, 张继权等系统总结农业气象灾害 风险评估方法及模型 ${ }^{[8]}$, 等。在方法论上, 农业气象 灾害风险评估方法也层出不穷, 有资料统计分析法 
Risk Analysis and Crisis Response in Big Data Era (RAC-16)

${ }^{[9-11]}$ 、数学模型法 ${ }^{[12-13]}$ 、实验机理模拟法 ${ }^{[14-16]}$ 、作物 模型模拟法 ${ }^{[17-18]} 、$ GIS 分析法 ${ }^{[19-20]}$, 等。可以发现, 这些研究大都局限于对作物的某种气象灾害或某几 种气象灾害风险进行分离式评估, 忽略了作物减产损 失往往是由于生长期内受到了多种气象灾害的综合 影响。因此, 农业气象灾害风险评估需要从微观层面 上研究作物生长期内各种极端气象要素事件共同作 用造成的作物减产。另一方面, 有关气象要素与作物 产量之间关系的研究也很多, 它们通常是借助相关分

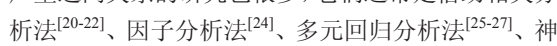
经网络法 ${ }^{[28]}$ 等统计方法, 直接建立生长期气象要素与 作物产量的关系模型, 研究大都是为作物产量预测服 务, 在研究视角上非真正意义的作物产量气象风险研 究。

本研究以安徽省淮北萧县玉米和长江流域来安 县水稻为典型案例, 在历史作物产量数据与气象数据 的支持下, 开展农业气象灾害风险识别与评估研究, 建立作物产量损失与气象要素极端异常之间的匹配 关系, 测算并排序各种气象灾害对作物产量损失的风 险度, 实现单气象灾害的风险评估。

\section{2. 数据准备}

本研究收集如下 3 类数据资料开展分析建模工作。

(1) 作物单产数据: 收集淮北萧县 1981 年至 2013 年的玉米单产数据、长江流域来安县 1981 年至 2013 年的水稻单产数据, 数据来源农业部县级农村 经济统计数据库。

(2) 气象要素数据: 收集淮北萧县和长江流域 来安县的县内气象站点自 1959 年至 2013 年气象要素 月观测数据, 具体包括: 月累计降水量、月最高温度、 月最低温度、月累计日照时数, 数据来源国家气象局。

（3）作物生长期数据：收集安徽省玉米和水稻
的种植生长期数据, 数据来源于安徽省农业统计年鉴 (2013 年)。

\section{3. 建模流程}

本研究的分析建模流程如图 1 所示。

\section{4. 数学建模}

\section{1. 单产去趋势}

影响水稻产量的因素很多, 主要有两类, 一类是包括 种子、化肥、农技水平、经营管理、政策、病虫害控 制等在内的非自然因素, 另一类则是自然因素。因此, 水稻产量可以分解为趋势产量和气象产量 ${ }^{[29]}$, 即:

$$
y_{t}=\hat{y}_{t}+u_{t}
$$

其中, $y_{t}$ 表示作物的实际单产 (吨/公顷); $\hat{y}_{t}$ 表示 作物的趋势单产 (吨/公顷), 代表非自然因素影响下 的单产; $u_{t}$ 表示作物的单产波动 (吨/公顷), 代表 自然因素影响下的单产。

常用的单产趋势模拟方法有回归分析法、滑动平 均法和直线滑动平均法。其中, 直线滑动平均法是一 种线性回归法与滑动平均法相结合的模拟方法, 它将 产量的时间序列在某个阶段内 (即滑动步长 $h$ ) 的 变化视为线性函数, 呈一直线。随着阶段的连续滑动, 直线不断变换位置, 后延滑动, 从而反映产量历史演 变趋势变化。本研究选用直线滑动平均法模拟趋势单 产, 并通过选择最佳滑动步长 $h$ 来优化趋势单产。

在确定趋势单产后, 为反映单产波动变化情况, 可进一步计算单产波动率 $\Delta y_{t}$, 即:

$$
\Delta y_{t}=\frac{y_{t}-\hat{y}_{t}}{\hat{y}_{t}}
$$

通常, 波动率正值代表增产, 负值表示减产。

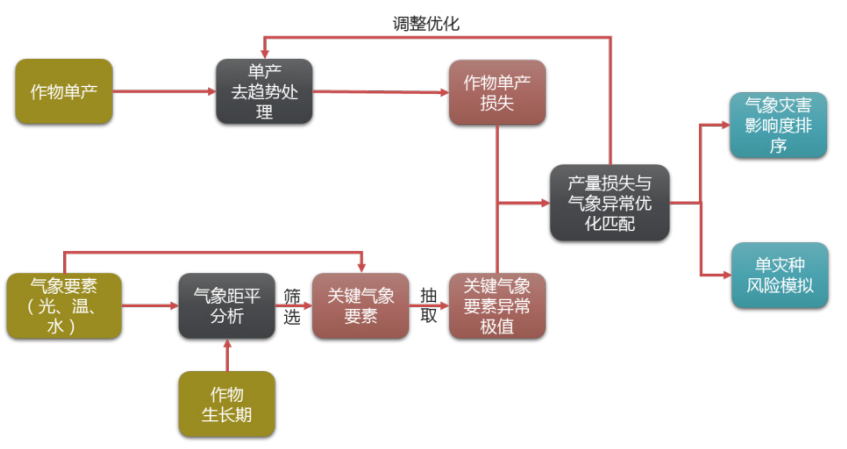

图 1. 研究的分析建模流程 


\section{Risk Analysis and Crisis Response in Big Data Era (RAC-16)}

\section{2. 气象距平分析}

在气象学中, 气象灾害从本质上看是气象要素发生极 端异常 ${ }^{[30]}$, 例如干旱对应的是降雨量过少异常、洪涝 对应的是降雨量过多异常。众所周知, 作物生长需经 历好几个月, 期间会受到多种气象灾害的同时影响。 为了更好地分析气象灾害对作物产量造成的影响, 有 必要选出作物生长期间内易发生异常的关键气象要 素。为此, 本研究选择距平分析来笁选关键气象要素。

所谓距平, 是指某一系列数值中的某一个数值与 该系列平均值的差, 分正距平和负距平。在气象上, 距平值可以用来确定某个时段或时次的数据相对于 该数据的某个长期平均值是高还是低。如果将历史上 某一气象要素单月距平的平均值进行比较的话, 便可 选出距平平均值较大的月份, 这些月份该气象要素最 可能发生异常, 具体如下:

(1) 选择某一类气象要素 $w$ (代表降水, 温度, 光照, 风速等), 计算该气象要素分月距平的年平均 值。由于气象要素可能存在正异常和负异常, 正、负 异常分别代表不同的气象灾害, 因此距平分析需要对 正、负距平分别进行考虑。以正异常为例, 具体表达 式如下:

$$
H\left(w_{m}^{+}\right)=\frac{\sum_{t=0}^{T}\left(w_{m, t}-\overline{w_{m}}\right)}{T^{+}}, \text {if }\left(w_{m, t}-\overline{w_{m}}\right)>0
$$

其中, $H\left(w_{m}^{+}\right)$表示气象要素 $w$ 第 $m$ 个月正距平的年 平均值 $(m=1, \ldots, 12), w_{m, t}$ 表示气象要素第 $t$ 年第 $m$ 个月的观测值, $\overline{w_{m}}$ 表示气象要素 $w$ 第 $m$ 个月所有 观测年的平均值, $T$ 表示气象要素所有观测年份数 量, $T^{+}$表示气象要素发生正异常的年份数量。

(2) 对气象要素 $w$ 分月距平平均值进行月度之 间的横向比较, 计算气象要素异常显著性指数。以正 异常为例, 具体表达如下:

$$
A\left(w_{m}^{+}\right)=\frac{H\left(w_{m}^{+}\right)-\overline{H\left(w^{+}\right)}}{\overline{H\left(w^{+}\right)}}
$$

其中, $A\left(w_{m}^{+}\right)$表示气象要素 $w$ 第 $m$ 个月的异常显著 性指数, $H\left(w_{m}^{+}\right)$表示气象要素 $w$ 第 $m$ 个月正距平的 年平均值 $(m=1, \ldots, 12), \overline{H\left(w^{+}\right)}$表示气象要素 $w$ 分 月正距平年平均值的 12 个月平均值。异常显著性指 数值越大, 说明该气象要素该月份发生异常的情况越 显著。

（3）设置一个异常显著性判断阈值(例如 0.1 ), 气象要素异常指数超出该阈值的月份可以认为一年 12 个月中气象要素易发生异常的月份。结合作物的 生长期, 在作物生长期范围内篮选出气象要素易发生
异常月份作为潜在影响作物生长的分月气象要素。将 所有类别的气象要素 (降水、温度、光照、风速等) 按照上述步骤进行分析, 便可获得作物生长期间内易 发生异常的关键气象要素集, 即:

$$
W=\left\{w_{1, m_{0}}^{+o r-}, \ldots, w_{g, m_{k}}^{+o r-}\right\}
$$

其中, $w_{g}$ 代表各类气象要素 (降雨量 $\mathrm{P}$, 温度 $\mathrm{T}$, 光照 $\mathrm{S}$, 风速 $\mathrm{W}$ 等), + 和 - 代表气象要素发生正异 常和负异常, $m_{k}$ 表示气象要素发生异常的月份。

\section{3. 产量损失与气象异常优化匹配}

正如前述, 气象灾害的实质是某种气象要素发生极端 异常。所谓异常, 就是偏离正常范围, 且偏离程度越 大, 异常就越极端, 对应的灾度也就越大。从常识上 看, 气象灾害灾度越大理应造成农作物的减产损失越 大。因此, 本研究将通过建立气象要素异常与作物减 产损失之间关系来识别作物气象风险。

\section{(1) 气象要素异常}

气象要素的月度异常可以通过判断气象要素月度观 测值偏离该气象要素月度历史平均观测值的程度来 识别, 即:

$$
\delta w_{g, m, t}^{+}=\left\{\begin{array}{l}
w_{g, m, t}-\overline{w_{g, m}}, \text { if }\left(w_{g, m, t}-\overline{w_{g, m}}\right) \geq 0 \\
0, \text { else }
\end{array}\right.
$$

其中, $d w_{g, m, t}^{+}$表示第 $g$ 种气象要素第 $t$ 年第 $m$ 月的正 异常偏离值 (偏离值越大越异常), $w_{g, m, t}$ 表示该气象 要素第 $t$ 年第 $m$ 月的观测值, $\overline{w_{g, m}}$ 表示该气象要素第 $m$ 月的历史平均观测值。负异常的表达类似。

同类气象要素的年度异常可以通过选取该气象 要素分月异常的极值来表示, 即:

$$
d w_{g, t}^{+}=\max \left(d w_{g, m_{0}, t}^{+}, \ldots, d w_{g, m_{k}, t}^{+}\right)
$$

其中, $d w_{g, t}^{+}$表示第 $g$ 种气象要素第 $t$ 年的正异常偏 离极值, $d w_{g, m, t}^{+}$表示该气象要素第 $t$ 年第 $m$ 月的正异 常偏离值, $d w_{g, n, t}^{+}$表示该气象要素第 $t$ 年第 $n$ 月的正 异常偏离值。负异常的表达类似。

为消除不同类气象要素之间量纲不同的影响, 需 
Risk Analysis and Crisis Response in Big Data Era (RAC-16)

对气象要素的年度异常进行归一化操作, 即:

$$
\bar{d} w_{g, t}^{+}=\frac{d w_{g, t}^{+}-\min \left(d w_{g}^{+}\right)}{\max \left(d w_{g}^{+}\right)-\min \left(d w_{g}^{+}\right)}
$$

其中, $\bar{d} w_{g, t}^{+}$表示第 $g$ 种气象要素第 $t$ 年的正异常偏离

归一化值, $\max \left(d w_{g}^{+}\right)$表示该气象要素正异常偏离的

历史最大值, $\min \left(d w_{g}^{+}\right)$表示该气象要素正异常偏离

的历史最小值。负异常的表达类似。

\section{（2）作物单产损失}

作物产量损失可以通过判断作物产量波动率偏离历 史最好增产率的程度来识别, 具体表达如下:

$$
d y_{t}=\left|\mathrm{V} y_{t}-\max \left(\mathrm{V} y_{t}\right)\right|
$$

其中, $d y_{t}$ 表示作物第 $t$ 年的单产损失率, $\mathrm{V} y_{t}$ 表示 作物第年的单产波动率, $\max \left(\mathrm{V} y_{t}\right)$ 表示作物历史单 产波动率的最大值。

\section{（3）关系优化匹配}

众所周知, 轻微程度的气象异常通常构不成气象灾害, 只有气象异常达到一定程度才会诱发气象灾害, 才有 可能对作物生产产生影响。因此, 需要在气象异常判 断上增设一个阈值, 超出该阈值的极端异常才可能诱 发气象灾害, 才可能导致作物单产损失。而这个阈值 并非固定不变, 不同类型气象要素的阈值有差异, 不 同地区的气象阈值有差异, 不同类型的作物因脆弱性 不同对应的气象阈值也有差异。因此, 在建模时, 可 以通过不断微调气象要素阈值来不断匹配气象要素 异常与产量损失之间线性关系, 通过寻找最大调整 $\mathrm{R}$ 方值找出最优匹配关系, 进而最终确定各气象要素阈 值和关系模型, 即:

$f_{o p}(\delta Y, \bar{\delta} W)=\left\{\begin{array}{l}\delta y=a_{1} * \bar{\delta} w_{1}^{+o r-}+\ldots+a_{g} * \bar{\delta} w_{g}^{+o r-}+a_{0} \\ \bar{\delta} w_{g}^{+o r-}= \begin{cases}\bar{\delta} w_{g}^{+o r-}, \text { if } & \bar{\delta} w_{g}^{+o r-} \geq \sigma_{w_{g}^{+o r-}} \\ 0, \text { if } & \bar{\delta} w_{g}^{+o r-}<\sigma_{w_{g}^{+o r-}}\end{cases} \\ R_{\text {adjusted }}^{2} \rightarrow \text { larg est }\end{array}\right.$

其中, $f_{o p}(d Y, \bar{d} W)$ 表示气象异常与产量损失的最优

线性匹配关系, $d y$ 表示表示作物的单产损失率,

$\bar{d} w_{g}^{+o r-}$ 表示第 $g$ 种气象要素正异常或负异常的归一

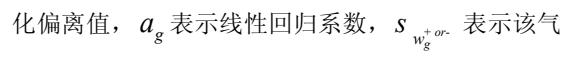

象要素正负异常的判断阈值, $R_{\text {adjusted }}^{2}$ (largest 表示 调整 R 方值达到最大。

此外, 作物单产损失率的计算与单产去趋势模型 密切相关, 本研究中直线滑动平均模拟法的步长取的 不同, 直接影响优化匹配关系。为此, 本研究采用步 长尝试法, 通过不断调整步长重复上述步骤, 直至找 到所有步长中最优匹配关系, 进而确定最佳步长与最 优模型, 即:

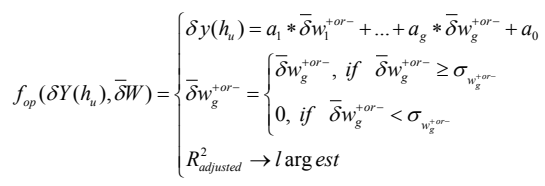

其中, $h_{u}$ 是最佳单产直线滑动去趋势步长。

\section{4. 气象灾害风险排序}

在气象异常和产量损失最优关系的基础上, 可以通过 气象要素的敏感性来对关键气象要素进行排序。气象 要素敏感性是指在其他气象要素正常时, 某一气象要 素的绝对异常对作物产量造成影响的程度, 程度越大 说明该气象要素的敏感性越高。结合公式 (11), 任 一气象要素敏感性可表达为:

$$
S_{w_{g}^{\text {orr }}}=\frac{\partial\left[\delta y\left(h_{u}\right)\right]}{\partial\left(\bar{\delta} w_{g}^{+o r-}\right)}=a_{g}
$$

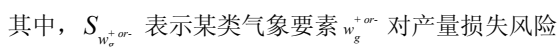
的敏感性系数。实质上, $S_{w_{g}^{+o r}}$ 等于关系模型中该气 象要素变量对应的系数 $a_{g}$ 。综合其他气象要素敏感 性系数, 该气象要素异常对作物单产损失风险的影响 度可进一步表达为:

$$
P_{w_{g}^{+a r r}}=\frac{S_{w_{g}^{+o r .}}}{S_{w_{1}^{+a r .}}+\ldots+S_{w_{g}^{+a r .}}}=\frac{a_{g}}{a_{1}+\ldots+a_{g}}
$$

由于某类气象要素异常在现实中对应的是某种气象 灾害, 因此各类气象要素异常对单产损失的影响度也 就是各种气象灾害对单产损失风险的影响度, 即:

$$
P_{H_{g}}=\frac{S_{H_{g}}}{S_{H_{1}}+\ldots+S_{H_{g}}}=\frac{a_{g}}{a_{1}+\ldots+a_{g}}
$$

其中, $H_{g}$ 表示气象要素 $w_{g}^{+o r}$ 正异常或负异常对应的 气象灾害类型。利用影响度可对该地区的气象灾害风 
Risk Analysis and Crisis Response in Big Data Era (RAC-16)

险进行排序, 影响度越高、风险就越大。

\section{5. 气象灾害风险模拟评估}

选择任一气象灾害 (通常选择风险度排序靠前的) $H_{g}$,

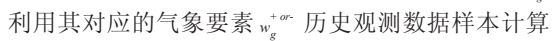
出该气象要素正异常或负异常偏离值历史样本:

$$
\left\{d w_{g, t_{0}}^{+o r-}, \ldots, d w_{g, t_{n}}^{+o r-}\right\}
$$

其中, $t_{0}, \ldots, t_{n}$ 表示有该气象要素观测的年份。运用 正态分布对该气象要素的概率密度函数进行估计, 具 体表达如下:

$$
\tilde{f}\left(\delta w_{g}^{+o r-}\right)=\frac{1}{\sqrt{2 \pi} \sigma} \exp \left(-\frac{\left(\delta w_{g}^{+o r-}-\mu\right)^{2}}{2 \sigma^{2}}\right)
$$

其中, $\tilde{f}\left(\delta w_{g}^{+o r-}\right)$ 表示气象要素正异常或负异常偏离 值 $d w_{g}^{+o r-}$ 的概率密度函数, $m$ 表示 $d w_{g}^{+o r-}$ 的历史样 本均值, $s$ 表示 $d w_{g}^{+o r-}$ 的历史样本方差。

通过假设重现期的方式可以模拟气象要素发生 极端异常, 即出现气象灾害。为此, 利用气象要素的 概率分布函数, 计算出重现期下 $T_{0}$ 的气象要素异常偏 离值 $d w_{g, T_{0}}^{+o r-}$, 具体表达如下:

$$
\delta w_{g, T_{0}}^{+o r-}=F^{-1}\left(1-\frac{1}{T_{0}}\right)
$$

其中, $F^{-1}$ 表示该气象要素正异常或负异常偏离值的 分布函数。假设其他气象要素不发生异常的情况下, 将该重现期下 $T_{0}$ 的气象要异常偏离值 $d w_{g, T_{0}}^{+}$代入 (11), 便可计算出作物单产损失率 $d y\left(w_{g, T_{0}}^{+o r}\right)$, 即:

$$
\delta y\left(w_{g, T_{0}}^{+o r-}\right)=\left\{\begin{array}{l}
a_{g} \cdot \delta w_{g, T_{0}}^{+o r-}+a_{0}, \text { if } \quad \delta w_{g, T_{0}}^{+o r-} \geq \sigma_{w_{g}^{\text {orr }}} \\
a_{0}, \text { if } \quad \delta w_{g, T_{0}}^{+o r-}<\sigma_{w_{g}^{+o r-}}
\end{array}\right.
$$

由于这里计算出的单产损失率是与历史最佳单产波 动率相比的结果, 在衡量风险损失时需将其调整为与 趋势单产之间的比较结果, 即:

$$
\nabla y\left(w_{g, T_{0}}^{+o r-}\right)=\left\{\begin{array}{l}
0, \text { if } w_{g, T_{0}}^{+o r-} \leq \max (\Delta y) \\
w_{g, T_{0}}^{+o r-}-\max (\Delta y), \text { else }
\end{array}\right.
$$

如果假设一组不同的重现期 $\left\{T_{0}, T_{1}, \ldots, T_{m}\right\}$, 便可模拟 出各种重现期该气象要素异常 (即对应的气象灾害) 造成的作物减产率, 即:

$$
\left\{\left(T_{0}, \nabla y\left(w_{g, T_{0}}^{+o r-}\right)\right), \ldots,\left(T_{m}, \nabla y\left(w_{g, T_{m}}^{+o r-}\right)\right)\right\}
$$

将上述信息绘制在图表上, 制作出该气象灾害不同重 现期下作物产量风险（减产率）图。

\section{5. 结果分析}

\section{1. 作物单产损失分析}

利用淮北萧县玉米单产时间序列数据和长江流域来 安县水稻单产时间序列数据, 利用直线滑动去趋势模 型对玉米和水稻单产进行去趋势分析, 获得两个县域 的玉米和水稻单产波动率, 并以历史最佳增产率为准, 计算两个县玉米和水稻单产损失率 (如图 2)。图中 可以看出, 萧县的玉米单产损失波动较为剧烈, 其中 1982 年、1987 年、2002 年出现较为严重减产损失; 来安县的水稻单产损失波动较为缓和, 其中 1994 年 和 2003 年出现较为严重减产损失。

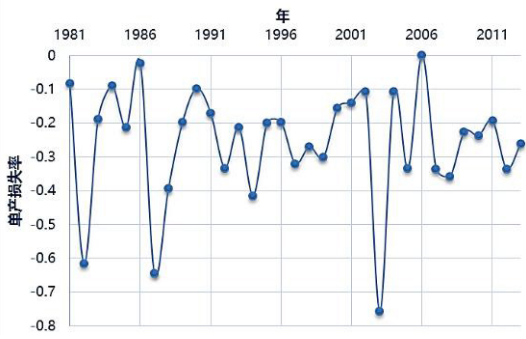

(a)萧县

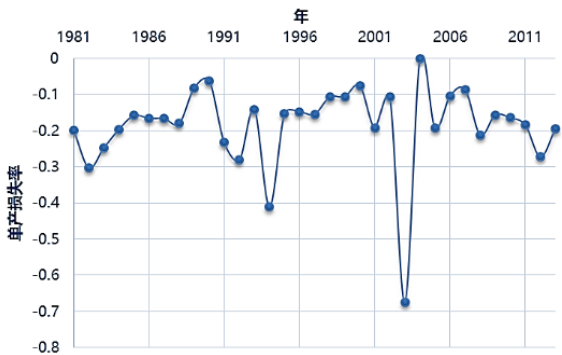

(b) 来安县

图 2. 萧县玉米和来安县水稻单产损失率年际变化

\section{2. 关键气象要素䈨选}

光 (光照 $S$ )、温 (温度 $T$ )、水 (降水量 $P$ ) 是影 响作物生长的三类气象要素, 而降水量正异常 $\left(P^{+}\right)$、 降雨量负异常 $\left(P^{-}\right)$、温度正异常 $\left(T^{+}\right)$、温度负 异常 ( $T^{-}$) 与光照负异常 ( $S^{-}$) 分别代表了影响作 物生长的五类气象灾害, 即洪涝、干旱、高温、低温 (冰冻) 和寡照 (连阴雨)。通过对萧县与来安县的 三类气象要素月观测数据的距平分析, 并结合当地玉 
Risk Analysis and Crisis Response in Big Data Era (RAC-16)

米和水稻的生长期 (玉米: 4 月到 8 月, 水稻: 4 月 到 9 月), 获得气象要素显著异常与作物生长期对比 图谱 (如图 3)。

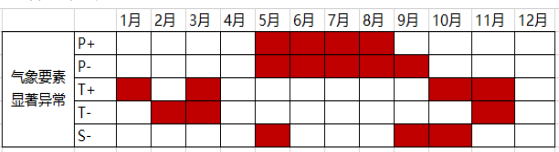

玉米生长期

(a)萧县

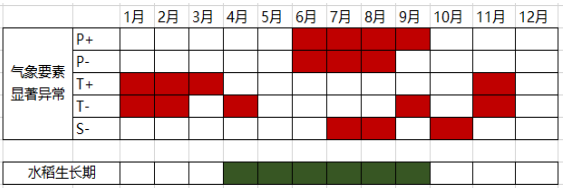

(b)来安县

图 3. 气象要素显著异常与作物生长期对比图谱

利用对比图谱可以选出萧县玉米和来安县水稻 的关键气象要素, 即:

(1) 萧县:

$$
W_{\text {Xiao }}=\left\{P_{5}^{+}, P_{6}^{+}, P_{7}^{+}, P_{8}^{+}, P_{5}^{-}, P_{6}^{-}, P_{7}^{-}, P_{8}^{-}, S_{5}^{-}\right\}
$$

(2) 来安县:

$$
W_{\text {LaiAn }}=\left\{P_{6}^{+}, P_{7}^{+}, P_{8}^{+}, P_{9}^{+}, P_{6}^{-}, P_{7}^{-}, P_{8}^{-}, S_{7}^{-}, S_{8}^{-}, T_{4}^{-}, T_{9}^{-}\right\}
$$

\section{3. 气象要素异常分析}

对各类气象要素异常月偏离值的年度极值进行选取, 获得气象要素异常的年度偏离极值, 并进行年度间的 归一化处理, 获得了萧县和来安县的气象要素异常的 年际度变化情况, 如图 4 所示。萧县的气象要素异常 年度波动较为剧烈, 其中 1982、1985、1993、1998、 2002 和 2003 年较为异常; 来安县的气象要素异常年 度波动较为缓和, 其中 1982、1987、1993、1996、 1999、2003 和 2006 较为异常。

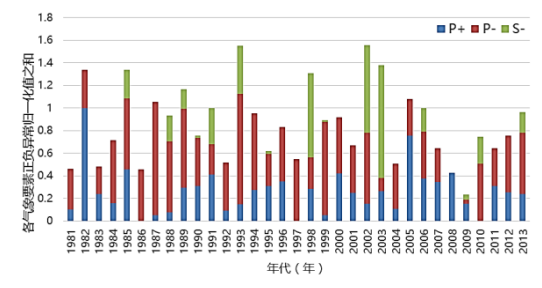

(a) 萧县

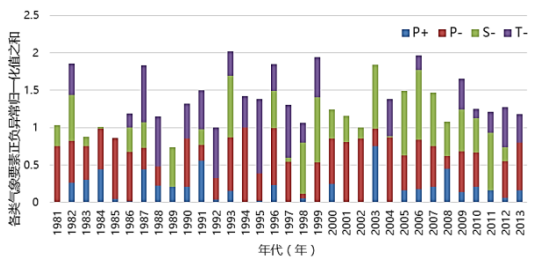

(b) 来安县

图 4. 气象要素异常年际变化

\section{4. 单产损失与气象异常最优匹配关系}

利用作物单产损失和气象异常时间序列数据, 通过证 整去趋势模型步长及各气象要素异常判断阈值, 对 物产量损失和气象异常的关系进行优化匹配, 获得产 县玉米和来安县水稻的最优匹配关系模型, 即:

(1) 萧县:

$$
\left\{\begin{array}{l}
\delta y\left(h_{u}\right)=0.69 * \bar{\delta} P^{+}+0.54 * \bar{\delta} P^{-}+0.87 * \bar{\delta} S^{-}-0.11 \\
\sigma_{P^{+}}=0.35 ; \quad \sigma_{P^{-}}=0.80 ; \quad \sigma_{S^{-}}=0.90 \\
h_{u}=9 \\
R^{2}=0.839
\end{array}\right.
$$

(2) 来安县:

$$
\left\{\begin{array}{l}
\begin{array}{l}
\delta y\left(h_{u}\right)=0.72 * \bar{\delta} P^{+}+0.29 * \bar{\delta} P^{-}+0.01 * \bar{\delta} S^{-} \\
\quad+0.04 * \bar{\delta} T^{-}+0.12
\end{array} \\
\sigma_{P^{+}}=0.75 ; \quad \sigma_{P^{-}}=0.9 ; \quad \sigma_{S^{-}}=0.65 ; \sigma_{T^{-}}=0.70 \\
h_{u}=8 \\
R^{2}=0.946
\end{array}\right.
$$

\section{5. 回溯检验}

为验证关系模型的有效性, 将历史气象观测数据代; 产量损失和气象异常最优关系模型, 计算出气象产点 损失, 并与实际产量损失进行比较, 检测气象产量 失与实际产量损失之间的关系（如图 5)。

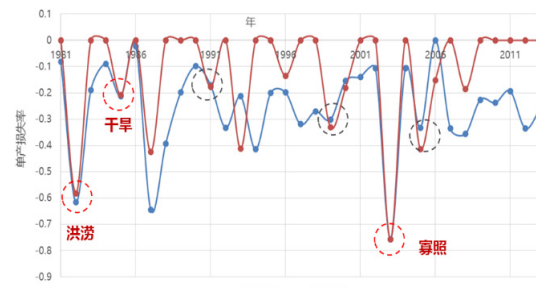


Risk Analysis and Crisis Response in Big Data Era (RAC-16)

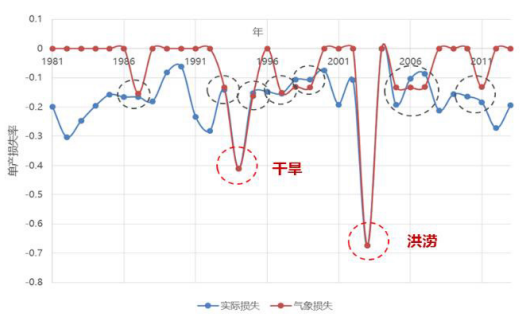

(b) 来安县

图 5. 气象产量损失与实际产量损失的历史回溯检验

图中可以看出, 气象产量损失与实际产量损失并 非完全匹配, 绝大部分气象产量损失略低于实际产量 损失。但从极端气象异常(即气象灾害) 的角度上看, 气象产量损失与实际产量损失有高度一致的匹配性。 例如, 在萧县, 1982 年洪涝、1985 年干旱、1999 年 干早、2003 年寡照、2005 年洪涝等极端气象事件造 成的单产损失与实际单产损失基本匹配; 在来安县, 1987 年低温、1994 年干早、1995 年低温和 2003 年 洪涝等极端气象事件造成的单产损失与实际单产损 失基本匹配。由此可见, 产量损失和气象异常最优关 系模型虽不能完全匹配气象与产量之间关系, 但却能 较好地印证气象极端异常与产量损失之间的关系, 客 观地反映出气象灾害对作物产量造成的损失。

\section{6. 气象灾害风险度排序}

利用气象异常与产量损失的最优匹配关系, 可对两个 县的作物产量损失的气象灾害风险度进行排序, 如图 6 所示。图中可以看出, 萧县玉米生产将面临塞照、 洪涝和干旱三类气象灾害影响, 且这三类气象灾害的 风险度相当。也就是说, 萧县玉米产量损失是三类气 象灾害的综合作用; 来安县水稻主要面临洪涝、干旱、 冷害和寡照四类气象灾害影响, 但其中洪涝风险度最 大, 几乎覆盖了近 $70 \%$ 的产量损失风险。由此可见, 来安县水稻产量损失主要来自于洪涝灾害的影响。

\section{7. 气象灾害风险模拟评估}

利用历史气象数据, 结合气象异常与产量损失的最优 匹配关系, 可对萧县玉米与来安县水稻的气象灾害风 险进行模拟评估。由于萧县三种气象灾害对产量风险 的贡献度基本相近, 因此对三种气象灾害分别进行模 拟评估, 如图 7 所示。图中可以看出, 寡照灾害重现 期在 40 年一遇以上开始出现减产, 到 100 年一遇以 上就完全绝收; 干旱灾害重现期在 10 年一遇以上开 始出现减产, 到 200 年一遇以上减产损失率将达到

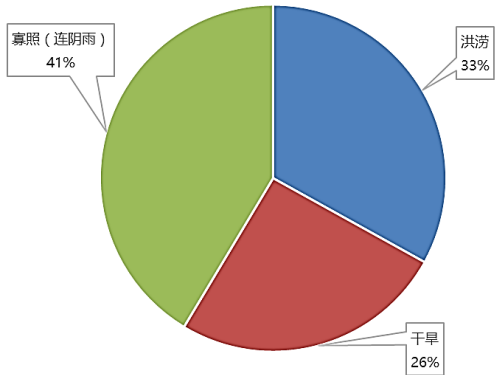

(a) 萧县

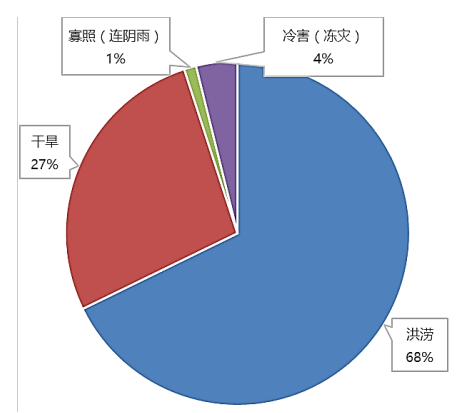

(b) 来安县

图 6. 气象灾害风险度排序

$27 \%$; 洪涝灾害重现期在 10 年一遇以上开始出现减 产, 到 200 年一遇以上减产损失率将达到 33\%。来安 县洪港风险覆盖了水稻产量损失风险的 70\%, 因此仅 对该县洪涝风险进行模拟评估, 如图 8 所示。图中可 以看出, 洪涝灾害重现期在 35 年一遇以上开始出现 减产, 到 200 年一遇以上减产损失率将达到 $95 \%$ 。

\section{6. 总结}

本研究以萧县玉米和来安县水稻为案例, 在历史作物 产量数据与气象数据的支持下, 通过优化匹配作物产 量损失与气象异常之间的关系, 开展农业气象灾害风 险识别与评估研究, 实现了气象灾害风险度排序和气 象灾害风险模拟评估, 为农业生产风险的评估与管理 提供了重要的技术支撑。

此外, 研究中还获得如下几个重要结论:

(1) 气象灾害不等同于农业气象灾害。农作物 具有自我修复的能力, 往往会出现气象灾害很大, 灾 情也很严重, 但经过一段时间的自我修复, 最终作物 的产量变化不大。这也印证了本研究中气象产量损失 
Risk Analysis and Crisis Response in Big Data Era (RAC-16)

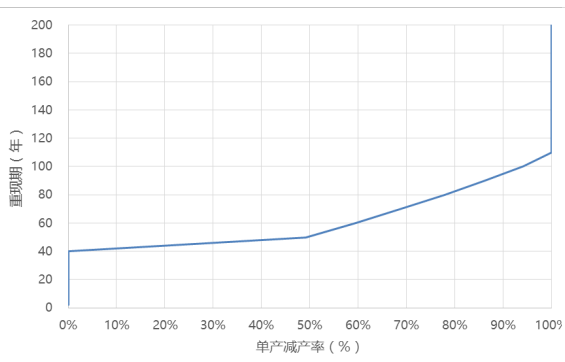

(a) 寡照风险

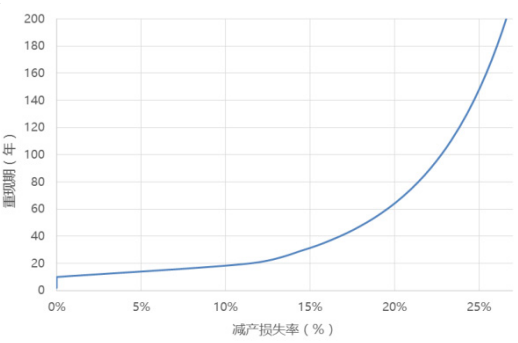

(b) 干旱风险

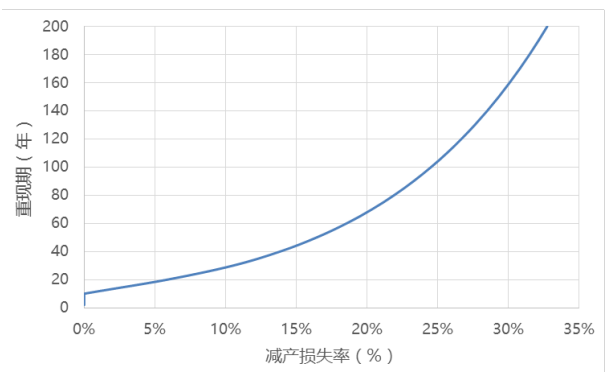

(c) 洪港风险

图 7. 萧县气象灾害风险模拟评估结果

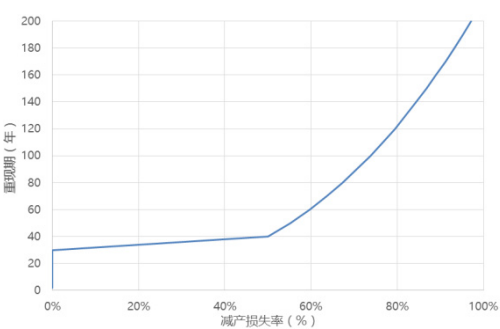

图 8. 来安县气象灾害风险模拟评估结果

与实际产量损失之间不能达到完全一致的关系。

(2) 农业产量损失不完全是气象灾害的影响。 造成作物产量波动不仅包括生产工具、政策等非自然 因素, 还包括气象灾害和病虫害等自然因素。在非自 然因素中, 气象灾害虽占了大部分比例, 但非完全决 定。换句话说，作物产量损失也有可能是其他方面的 影响, 例如病虫害。这也印证了本研究中出现非极端 气象灾害损失会低于实际产量损失。
(3) 气象灾害对农业产量的损失影响是综合性 的。作物生长期间会受到多种气象灾害(干旱、洪涝、 冷害等) 的影响, 这种影响往往是综合性的。因此, 一些研究忽略气象灾害综合性影响, 单纯建立一种气 象灾害风险模型是不科学。这便是本研究中采用全部 气象要素输入建模的重要出发点, 结论也得到了相应 的印证。

\section{Acknowledgements}

This study was supported by National "Twelfth Five-Year" Plan for Science \& Technology Support (2014BAL07B03-02), Beijing Municipal Science and Technology Project (Z141100002314007), National Natural Science Foundation of China (41471426) and Research Project from China Property \& Casualty Reinsurance Company LTD.

\section{致谢}

本研究得到了科技部“十二五”科技支撑子课题 
(2014BAL07B03-02)，北京市科技计划课题 （Z141100002314007），国家自然科学基金面上项 目 (41471426) 和中国财产再保险有限责任公司委托 课题（农业灾害易损性分析）资助。

\section{参考文献}

[1] 林燕, 于冷. 中国粮食产量波动分析. 吉林农 业大学学报，2002，28(3):346-350

[2] 张宇. 近 40 年来我国粮食产量变化特征初步 分析. 中国农业气象, 1995, 16(3):1-4

[3] S.J. Guo. The Meteorological Disaster Risk Assessment Based on the Diffusion Mechanism. Journal of Risk Analysis and Crisis Response. 2012, 2(2): 124-130

[4] 杜鹏, 李世奎. 农业气象灾害风险分析初探. 地理学报, 1998，53(3): 202-208

[5] 李世奎，霍治国，王素艳，等。农业气象灾害 风险评估体系及模型研究. 自然灾害学报, 2004, 13(1): 77-87

[6] 李志明, 藏俊岭, 焦仁庆. 农业气象灾害风险 评估研究综述. 现代农业科技, 2009, (14): 269-270

[7] 王丽媛, 于飞. 农业气象灾害风险分析及区划 研究进展．贵州农业科学，2011，39(11)：84-88

[8] 张继权, 李宁. 主要气象灾害风险评价与管理 的数量化方法及其应用 $[\mathrm{M}]$. 北京: 北京师范 大学出版社, 2007

[9] 王春乙, 娄秀荣, 王建林. 中国农业气象灾害 对作物产量的影响. 自然灾害学报, 2007,16(5): $37-43$

[10] 王光宇, 安徽省农业气象灾害粮食损失率评估. 农业系统科学与综合研究, 2008,24(3): 330-332

[11] 陈怀亮, 邓伟, 张雪芬, 等. 河南小麦生产农 业气象灾害风险分析与区划. 自然灾害学报, 2006,15(1): 135-143

[12] 王积全，李维德. 基于信息扩散理论的干旱区 农业旱灾风险分析一一以甘肃省民勤县为例. 中国农业气象，2007,28(4)：440-442

[13] 潘护林. 山东省农业气象灾害灾情统计特征与 灰色关联分析. 西北师范大学学报: 自然科学 版, 2008,44(5): 94-98

[14] 刘玲, 郭建平, 高素华. 低温、干旱并发对玉 米影响的评估研究. 气象, 2006,32(4): 116-120

[15] 高素华, 刘玲. 低温、干旱胁迫对抽雄期玉米 叶片光化效率和光合作用速率的影像. 气象, 2007,33(4):88-91

[16] 陈振林, 张建平, 王春乙, 等. 应用 WOFOST 模型模拟低温与干旱对玉米产量的 综合影响. 中国农业气象, 2007,28(4): 440-442

[17] 董姝娜，庞泽源，张继权，等. 基于 CERES Maize 模型的吉林西部玉米干旱脆弱性曲线研 究. 灾害学, 2014,29(3):115-119

[18] 贾慧聪，王静爱，潘东华，等. 基于 EPIC 模型
的黄淮海夏玉米旱灾风险评价. 地理学报, 2011,66(5):643-651

[19] 罗培. GIS 支持下的气象灾害风险评估模型. 自然灾害学报，2007,16(1): 40-43

[20] 赵霞, 王平, 龚亚丽, 等. 基于 GIS 的内蒙古 中部区域洪水灾害风险评估. 北京师范大学学 报：自然科学版，2007,43(6)：666-669

[21] 杨晓华, 曹天堂, 杨小利. 影响平凉金果产量 的生态气象因子及其变化趋势. 安徽农业科 学, 2009, 37(27): 13033-13036

[22] 罗丽华, 陈桂华, 胡英, 等. 气象因素与早稻 产量因子的相关性分析. 自然资源学报, 2010，25(10): 1718-1726

[23] 陈彦虎, 顾宁, 刘静, 等. 宁夏石嘴山市枸杞 产量与气象条件的关系. 安徽农业科学, 2012, 40(27): 13508-13511

[24] F.M. Chmieleki, W.Kohn. Impact of weather on yield components of winter rye over 30 years. Agricultural and Forest Meteorology. 2000, 102: 253-261

[25] 彭九慧, 杨梅, 陆倩, 等. 玉米干旱等级划分 及气象产量评估方法. 环境科学与技 术,2012,35(12J):137-139

[26] 范磊, 郑国清, 赵全志, 等. 河南省水稻气象 灾害因子分析及主要灾害发生区划研究. 中国 农业资源与区划，2013，34(6): 162-168

[27] M. G. Pereira, L. Caramelo, C. Gouveia. Assessment of weather-related risk on chestnut productivity. Nat. Hazards Earth Syst. Sci., 2011, 11: 2729-2739

[28] 乔加新, 周森金金, 马季. 基于 $\mathrm{BP}$ 神经网络的 农业气象产量预报系统. 微计算机信息, 2009,25(12-2):44-46

[29] 张峭, 王克. 农作物生产风险评估的方法和模 型. 农业展望, 2007, 3(8): 7-10

[30] 周淑贞, 张如一, 张超. 气象学与气候学 $[\mathrm{M}]$. 北京：高等教育出版社, 1997 